\title{
Indirect Recognition of Donor HLA-DR Peptides in Organ Allograft Rejection
}

\author{
Zhuoru Liu, ${ }^{*}$ Adriana I. Colovai, ${ }^{*}$ Sorina Tugulea, ${ }^{*}$ Elaine F. Reed, ${ }^{*}$ Peter E. Fisher, ${ }^{\star}$ Donna Mancini, ${ }^{\S}$ Eric A. Rose, ${ }^{\ddagger}$ \\ Raffaello Cortesini," Robert E. Michler, ${ }^{\ddagger}$ and Nicole Suciu-Foca* \\ * College of Physicians and Surgeons of Columbia University, *Department of Pathology, ${ }^{\ddagger}$ Department of Surgery, ${ }^{\S}$ Department of \\ Internal Medicine, New York 10032; and ${ }^{\|}$Universita' Degli Studi di Roma La Sapienza, Istituto Di II Clinica Chirurgica, Servizio \\ Trapianti D'Organo, Rome, Italy
}

\begin{abstract}
To determine whether indirect allorecognition is involved in heart allograft rejection $T$ cells obtained from peripheral blood and graft biopsy tissues were expanded in the presence of IL-2 and tested in limiting dilution analysis (LDA) for reactivity to synthetic peptides corresponding to the hypervariable regions of the mismatched HLA-DR antigen(s) of the donor. Serial studies of 32 patients showed that $\mathrm{T}$ cell reactivity to donor allopeptides was strongly associated with episodes of acute rejection. The frequency of allopeptide reactive $T$ cells was $\mathbf{1 0 - 5 0 - f o l d ~ h i g h e r ~ i n ~ t h e ~ g r a f t ~ t h a n ~}$ in the periphery indicating that $T$ cells activated via the indirect allorecognition pathway participate actively in acute allograft rejection. In recipients carrying a graft differing by two HLA-DR alleles the response appeared to target only one of the mismatched antigens of the donor. Indirect allorecognition was restricted by a single HLA-DR antigen of the host and directed against one immunodominant peptide of donor HLA-DR protein. However, intermolecular spreading was demonstrated in patients with multiple rejection episodes by showing that they develop allopeptide reactivity against the second HLA-DR antigen. These data imply that early treatment to suppress $T$ cell responses through the indirect pathway of allorecognition, such as tolerance induction to the dominant donor determinant, may be required to prevent amplification and perpetuation of the rejection process. (J. Clin. Invest. 1996. 98:1150-1157.) Key words: allopeptide $\cdot$ alloreactivity $\bullet$ acute rejection $-\mathrm{T}$ cell determinants $\bullet$ MHC-restriction
\end{abstract}

\section{Introduction}

The long-term function of organ allografts is often compromised by rejection, a complex phenomenon which involves both the cellular and the humoral arms of the immune response. The mechanism of allograft rejection is not completely understood, although it has become increasingly clear that re-

Address correspondence to Dr. Nicole Suciu-Foca, College of Physicians and Surgeons, Columbia University, Department of Pathology, 630 West 168th Street, P \& S 14-403, New York, NY 10032. Phone: 212-305-6941; FAX: 212-305-3429.

Received for publication 11 April 1996 and accepted in revised form 2 July 1996.

J. Clin. Invest.

(C) The American Society for Clinical Investigation, Inc. 0021-9738/96/09/1150/08 \$2.00

Volume 98, Number 5, September 1996, 1150-1157 cipient $\mathrm{T}$ helper $(\mathrm{Th})^{1}$ cells become activated upon direct recognition of $\mathrm{MHC} /$ peptide complexes present on the membrane of passenger dendritic cells of donor origins (1-4). This vigorous response, which appears to violate the rule of self MHC restriction, is driven primarily by antigenic mimicry (5, 6). In nonsensitized transplant recipients, $T$ cells activated via the direct allorecognition pathway are thought to be important for initiation of early acute rejection. However, these directly activated $\mathrm{T}$ cells seem to be less critical at later times, following departure of donor dendritic cells from the graft, because upon recognition of donor MHC molecules on "nonprofessional" antigen presenting cells (APCs) that lack co-stimulatory elements, they may become anergized (7-10).

More recently, several lines of evidence have indicated that the indirect recognition pathway, which describes the stimulation of recipient $\mathrm{T}$ cells by allopeptides processed and presented on self-MHC expressed by recipient APCs, is a major contributor to rejection. Thus, during rejection of skin, kidney or heart allografts, $T$ cells recognizing processed forms of donor MHC antigens associated with host restriction elements were detected in the primary lymphoid organs of mice and rat recipients (11-13). Animals immunized with soluble class I or class II allogeneic MHC molecules or with synthetic MHC allopeptides were capable of accelerated rejection of skin allografts (14-16). Studies using MHC class II deficient mice as donors showed that in the absence of direct recognition $\mathrm{T}$ cells activated via the indirect pathway initiate rapid skin allograft rejection $(17,18)$. Alloreactive, self $\mathrm{MHC}$ restricted $\mathrm{T}$ cells were shown to provide the lymphokines required for the generation of cytotoxic T lymphocytes (CTL), alloantibodies and delayed-type hypersensitivity (DTH) responses $(9,15,17-19)$.

In the human model it has been demonstrated that two distinct populations of $\mathrm{T}$ cells, one involved in the direct and the other in the indirect recognition pathway, are activated after mixed lymphocyte culture (MLC) stimulation (20). Furthermore, $\mathrm{T}$ cells immunized in vitro with synthetic allopeptides respond specifically to the native alloantigen in the presence of self-APCs (21-24).

Both in mice and in humans, $\mathrm{T}$ cell proliferation to an allogeneic MHC protein was limited to a single dominant determinant and restricted by a self-HLA-DR molecule (10, 21, 24, $25)$. $T$ cell receptor (TCR)-V $\beta$ gene usage by $\mathrm{T}$ cells responding to the dominant allopeptide was also shown to be limited $(21,26)$. This suggests that indirect recognition is amenable to specific immunointervention $(9,10,13,24)$.

1. Abbreviations used in this paper: APCs, antigen presenting cells; CTL, cytotoxic T lymphocytes; DTH, delayed type hypersensitivity; EMB, endomyocardial biopsies; LDA, limiting dilution analysis; r, recombinant; TCR, T cell receptor; Th, T helper. 
A detailed understanding of when and how the indirect pathway becomes activated in immunosuppressed organ allograft recipients should provide valuable insight into the development of strategies to block $\mathrm{T}$ cell alloreactivity through the indirect pathway.

Because allopeptide-specific $\mathrm{T}$ cells require that donor alloantigens be shed from the graft, proteolyzed and the resulting fragments bound to an MHC class II molecule of the host, it is important to establish whether their activation is the cause or consequence of early acute rejection and whether they recognize single or multiple determinants of donor HLA-DR antigens. To address these questions, we have evaluated the frequency of activated $\mathrm{T}$ cells recognizing donor allopeptides, in peripheral blood and biopsy tissue of heart allograft recipients during the early posttransplantation period. In vivo activated T cells were expanded in IL-2 and tested in LDA for reactivity to synthetic peptides corresponding to each of the mismatched HLA-DR antigens of the donor. The results provide evidence to support the role of the indirect recognition pathway in rejection. The data also suggest that one of the mismatched HLADR antigens is preferentially targeted by alloreactive $\mathrm{T}$ cells. Selective immunosuppression may be required for ablation of the immune response to this specific determinant.

\section{Methods}

Patient specimens. 32 heart recipients (28 male and 4 females) were recruited for these studies during the first $10 \mathrm{wk}$ after transplantation. All gave informed consent under the auspices of the appropriate Institution Review Board. Patients were treated with cyclosporin A, prednisone and azathioprine. Endomyocardial biopsies (EMB) were performed routinely for monitoring rejection according to a standard time schedule (27). Four biopsy fragments were processed for histologic analysis and one was made available for immunologic studies (27). Blood specimens were obtained from the patients at the time of EMB. LDA studies were initiated between the 1st and 2nd week on 12 patients, between the 3rd and 4th week on 11 patients, and between week 5 and 10 on 9 patients. Acute rejection, diagnosed on biopsies as histologic grade 1B, 2 or 3A according to Billingham's criteria (28), was treated with increased doses of immunosuppression.

HLA typing. All recipients and donors were typed for HLA-DR antigens by conventional serology and by molecular methodology using PCR-SSOP (sequence specific-oligonucleotide probe).

Peptide synthesis. Synthetic peptides corresponding to residues $1-19,21-39,62-80$ of DR $\beta 1$ chain from 32 HLA-DR alleles (DR $\beta 1 * 0101, \mathrm{DR} \beta 1 * 0102, \mathrm{DR} \beta 1 * 0301, \mathrm{DR} \beta 1 * 0302, \mathrm{DR} \beta 1 * 0401$, DR $\beta * 0402, \quad$ DR $\beta * 0403, \quad$ DR $\beta 1 * 0404, \quad$ DR $\beta * 0405, \quad$ DR $\beta 1 * 0407$, DR $\beta 1 * 0408$, DR $\beta 1 * 0701$, DR $\beta 1 * 0801$, DR $\beta 1 * 0802$, DR $\beta 1 * 0803$, DR $\beta 1 * 0804$, DR $\beta 1 * 0901, \operatorname{DR} \beta 1 * 1001, \operatorname{DR} \beta 1 * 1101, \operatorname{DR} \beta 1 * 1102$, DR $\beta 1 * 1104, \mathrm{DR} \beta 1 * 1201, \mathrm{DR} \beta 1 * 1301, \mathrm{DR} \beta 1 * 1302, \mathrm{DR} \beta 1 * 1303$, DR $\beta 1 * 1401, D R \beta 1 * 1402$, DR $\beta 1 * 1501$, DR $\beta 1 * 1502$, DR $\beta 1 * 1503$, DR $\beta 1 * 1601$, and DR $\beta 1 * 1602$ ) (29) were obtained from Chiron Mimotopes (San Diego, CA) and Peptide Innovation (Raleigh, NC). The purity of peptides was higher than $90 \%$, as indicated by HPLC and mass spectrometry. Synthetic peptides were dissolved in RPMI 1640 medium at a concentration of $2 \mathrm{mg} / \mathrm{ml}$. Before use in this study all peptides were tested in LDA for their ability to stimulate alloreactivity of PBMC from healthy members of our HLA-DR reference panel.

Limiting dilution analysis of allopeptide reactive $T$ cells. The frequency of allopeptide reactive T cells in the peripheral blood and biopsy was measured in LDA. The methods used for LDA were essentially identical except for the fact that to obtain a sufficient number of cells, T cells from biopsy tissue had to be expanded for one week in medium with IL-2 before testing in LDA. Also, while cells from the peripheral blood were tested in LDA at concentrations ranging from
1 to $4 \times 10^{4}$ cells/well, cells from biopsy tissue were tested at concentrations ranging from 2 to $8 \times 10^{2}$ cells/well given their limited number $\left(\sim 100,000 \mathrm{~T}\right.$ cells per $1 \mathrm{~mm}^{3}$ biopsy).

Briefly, PBMCs were grown for $7 \mathrm{~d}$ in round bottom 96-well trays at concentrations of $4 \times 10^{4}, 2 \times 10^{4}, 1 \times 10^{4}$ per well ( 24 wells for each concentration) in RPMI 1640 medium supplemented with $10 \%$ human serum (Sigma Chemical Co., St. Louis, MO) and 50 units recombinant (r)IL-2/ml (Boehringer Mannheim, Indianapolis, IN.), as described by Zhang et al. (30). On day 7, plates were washed three times and each culture was split into four aliquots. Two plates were used for testing $\mathrm{T}$ cell reactivity to a cocktail of peptides $(1 \mu \mathrm{M}$ of each peptide) corresponding to each of the mismatched HLA-DR antigens of the donor in the presence of irradiated autologous PBMCs $\left(5 \times 10^{4} /\right.$ well). The third plate, to which only self PBMCs (without peptides) were added, served as a negative control. After $48 \mathrm{~h}$ of incubation, the cultures were labeled with ${ }^{[3 \mathrm{H}]} \mathrm{TdR}$ and harvested $18 \mathrm{~h}$ later. Wells were scored positive if cpm in cultures with allopeptides exceeded 2000 and were at least three times higher than cpm in replicate control cultures without the peptides. The fourth plate was left unlabeled and kept for T cell expansion and HLA-DR restriction studies. Th frequency was calculated as previously described $(23,30)$.

Graft tissue $\left(1 \mathrm{~mm}^{3}\right.$ piece $)$ was placed in 24-well plates containing $1 \times 10^{6}$ autologous APCs (irradiated with 3000rad) in RPMI 1640 medium supplemented with low concentrations of rIL-2 $(5 \mathrm{U} / \mathrm{ml})$ and $10 \%$ human serum. After $7 \mathrm{~d}$ of expansion, $\mathrm{T}$ cells were collected, washed and plated at concentrations of 800,400 , and 200 cells/well in round bottom 96-well tray ( 24 replicate cultures for each concentration). Irradiated autologous APCs $\left(5 \times 10^{4} /\right.$ well $)$ in RPMI 1640 medium supplemented with 50 units (r)IL-2/ml were added to each well. On day 7 the wells were split as above and T cell reactivity to allopeptides was tested in a 3-d blastogenesis assay.

Analysis of dominant allopeptide determinants and of restriction elements. To identify the dominant peptide(s) recognized by $\mathrm{T}$ cells in LDA T cell lines were generated and tested for reactivity to each individual peptide comprised in the stimulating mixture of donor-specific allopeptides. The culture conditions required for generation and propagation of allopeptide-specific human $\mathrm{T}$ cell lines have been previously described (21). Briefly, cells from cultures corresponding to wells in which $\mathrm{T}$ cell reactivity to donor allopeptides was detected were expanded in 24-well plates in the presence of autologous APCs $\left(1 \times 10^{6} /\right.$ well $)$, stimulating peptide mixture $(1 \mu \mathrm{M}$ of each peptide $)$ and rIL-2 $(20 \mathrm{U} / \mathrm{ml})$. Cultures were restimulated every $14 \mathrm{~d}$ by addition of irradiated APCs, peptide mixture and IL-2. After three or four stimulations the resulting $\mathrm{T}$ cell lines $\left(2 \times 10^{4} \mathrm{~T}\right.$ cells/well $)$ were tested for reactivity to the individual peptides comprised in the mixture $(1 \mu \mathrm{M})$, in the presence of APCs $\left(5 \times 10^{4} /\right.$ well $)$ from the recipient and from hemi-allogeneic donors sharing one HLA-DR antigen with the recipient. Allopeptide-reactivity was measured in $3 \mathrm{~d}$ blastogenesis assays as previously described (21).

Statistics. Statistical analyses were performed using BMDP statistical software (BMDP Statistical Software, Inc., Los Angeles, CA). The incidence of rejection one month following LDA was calculated by the product-limit method. Differences between groups were compared using Breslow statistics. A test of linear trend was used to analyze the relationship between allopeptide reactivity and progression of acute rejection (31).

\section{Results}

Activation of the indirect recognition pathway during allograft rejection. To determine whether indirect allorecognition contributes to allograft rejection, T cells obtained from the peripheral blood of 32 heart transplant recipients were expanded in medium supplemented with rIL-2 and then tested for reactivity to synthetic allopeptides corresponding to the hypervariable regions of the mismatched HLA-DR antigens of the donor. A minimum of two serial PBMC specimens (mean 3.5) 


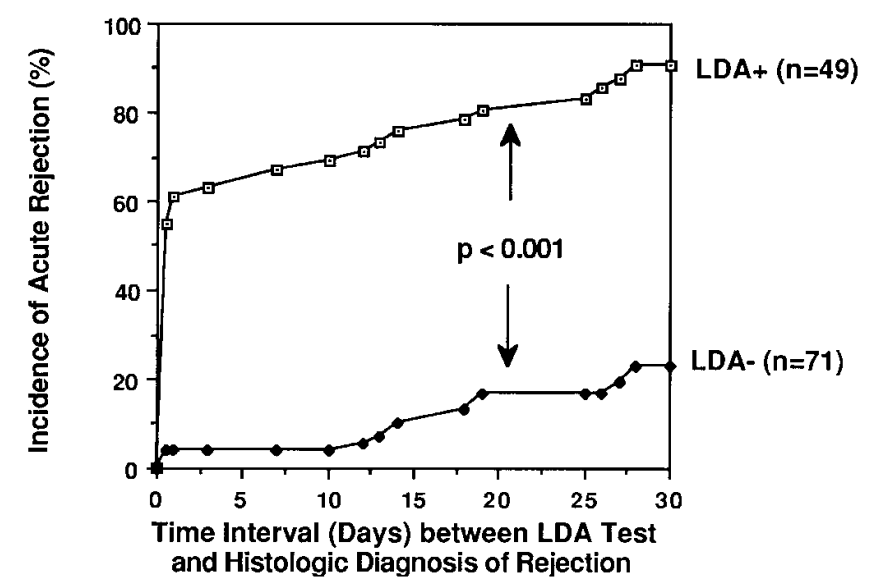

Figure 1. Association between acute rejection and Th reactivity to donor allopeptides. Serial blood samples were obtained from heart transplant recipients and tested in LDA for reactivity to donor HLADR peptides. LDA was considered positive if more than $1.5 \times 10^{-6}$ Th cells reactive to one or both of the donor's HLA-DR antigens were detected. Rejection was monitored by EMB and considered to be present when graded histologically $1 \mathrm{~B}$ or higher. Incidence of rejection one month after LDA was calculated by the product-limit method.

were obtained from each patient with elapsed intervals of 1 to 12 wk (mean $4.1 \mathrm{wk}$ ) between collections. After $7 \mathrm{~d}$ of expansion in medium containing rIL-2, T cells were tested in LDA for reactivity against synthetic peptides corresponding to each HLA-DR antigen of the donor. T cell proliferation in response to one or both sets of donor DR peptides was considered indicative of in vivo activation of the indirect recognition pathway. 49 out of the 120 samples of PBMCs studied in LDA con-
Table I. Relationship between T Cell Reactivity to Donor Allopeptide and Clinical Status

\begin{tabular}{|c|c|c|c|c|c|c|}
\hline \multirow[b]{2}{*}{ Specimen } & \multirow[b]{2}{*}{ LDA results } & \multicolumn{4}{|c|}{ Time of LDA Testing } & \multirow[b]{2}{*}{ Total } \\
\hline & & $\begin{array}{l}\text { Before } \\
\text { Onset }\end{array}$ & Concommitant & Resolving & $\begin{array}{l}\text { Quiescence: } \\
\text { no rejection }\end{array}$ & \\
\hline \multirow[t]{3}{*}{ PBMC } & Positive & 18 & 22 & 6 & 2 & 49 \\
\hline & Negative & 10 & 3 & 11 & 47 & 71 \\
\hline & Total & 28 & $\begin{array}{c}25 \\
P<0.001\end{array}$ & 17 & 50 & 120 \\
\hline \multirow[t]{3}{*}{ Graft } & Positive & 2 & 6 & 1 & 1 & 10 \\
\hline & Negative & 1 & 1 & 0 & 11 & 13 \\
\hline & Total & 3 & $\begin{array}{c}7 \\
P<0.002\end{array}$ & 1 & 12 & 23 \\
\hline
\end{tabular}

IL-2 expanded T cells from the peripheral blood and graft biopsy tissue obtained at various times following transplantation were tested in LDA for reactivity to donor allopeptides. The number of specimens showing allopeptide-reactive T cells is indicated. The relationship between T cell reactivity to donor allopeptides and clinical status was calculated using the test of linear trend (31).

tained allopeptide reactive $\mathrm{T}$ cells. The frequency of acute rejection episodes, occurring one month following the LDA test, was significantly higher when allopeptide reactive $\mathrm{T}$ cells were present in the circulation, than when they were absent $(P<0.001)$ (Fig. 1). IL-2 expanded T cells from 20 healthy controls showed no proliferation to mixtures of synthetic allopeptides (data not shown).

14 recipients had concomitant PBMC and biopsy specimens. Tests of linear trend revealed a significant correlation between allopeptide reactivity in the periphery $(P<0.001)$

Table II. Frequency of Donor-specific, Self-MHC restricted T Cells in the Graft and in the Periphery

\begin{tabular}{|c|c|c|c|c|c|c|c|c|}
\hline \multirow{3}{*}{ Patient } & \multicolumn{2}{|c|}{ HLA-DR } & \multirow{3}{*}{$\begin{array}{l}\text { Time of study } \\
\text { (weeks after } \\
\text { transplantation) }\end{array}$} & \multirow{3}{*}{ Histologic grade } & \multicolumn{4}{|c|}{ Frequency of allopeptide specific T cells } \\
\hline & \multirow[t]{2}{*}{ Recipient } & \multirow[t]{2}{*}{ Donor } & & & \multicolumn{2}{|c|}{ Graft } & \multicolumn{2}{|c|}{ Periphery } \\
\hline & & & & & DR1 Peptide & DR 3 Peptide & DR1 Peptide & DR 3 Peptide \\
\hline \multirow[t]{4}{*}{ W.O. } & $0701 / 0803$ & $0101 / 0301$ & 6 & $1 \mathrm{~A}$ & $1.1 \times 10^{-4}$ & 0 & $5.7 \times 10^{-6}$ & 0 \\
\hline & & & 8 & $3 \mathrm{~A}$ & $3.7 \times 10^{-4}$ & 0 & $3.6 \times 10^{-6}$ & 0 \\
\hline & & & 12 & $1 \mathrm{~A}$ & 0 & 0 & 0 & 0 \\
\hline & & & & & DR1 Peptide & DR 14 Peptide & DR1 Peptide & DR 14 Peptide \\
\hline \multirow[t]{4}{*}{ I.P. } & $0404 / 1104$ & $0101 / 1401$ & 6 & 2 & ND & ND & $7.4 \times 10^{-6}$ & 0 \\
\hline & & & 8 & $3 \mathrm{~A}$ & $4.3 \times 10^{-4}$ & 0 & $8.0 \times 10^{-6}$ & 0 \\
\hline & & & 12 & $1 \mathrm{~B}$ & $3.3 \times 10^{-4}$ & 0 & $6.5 \times 10^{-6}$ & 0 \\
\hline & & & & & DR7 Peptide & DR 3 Peptide & DR7 Peptide & DR 3 Peptide \\
\hline \multirow[t]{6}{*}{ D.R. } & 1101/1101 & 0301/0701 & 2 & $1 \mathrm{~A}$ & 0 & 0 & 0 & 0 \\
\hline & & & 13 & $1 \mathrm{~B}$ & $2.6 \times 10^{-4}$ & 0 & $4 \times 10^{-6}$ & 0 \\
\hline & & & 14 & $1 \mathrm{~B}$ & ND & ND & $3.1 \times 10^{-6}$ & 0 \\
\hline & & & 16 & 2 & $2.7 \times 10^{-4}$ & 0 & $6.0 \times 10^{-6}$ & 0 \\
\hline & & & 17 & 0 & 0 & 0 & 0 & 0 \\
\hline & & & & & DR8 Peptide & DR10 Peptide & DR8 Peptide & DR10 Peptide \\
\hline \multirow[t]{2}{*}{ B.M. } & 0301/0701 & $08 / 10$ & 2 & $3 \mathrm{~A}$ & $0.9 \times 10^{4}$ & 0 & $1.8 \times 10^{-6}$ & 0 \\
\hline & & & 8 & 0 & 0 & 0 & 0 & 0 \\
\hline
\end{tabular}

T cells from the peripheral blood and biopsy tissue were expanded in rIL-2 and then tested in LDA for reactivity to synthetic peptides corresponding to each HLA-DR antigen of the donor. Zero indicates that the frequency of allopeptide reactive T cells was less than $1.5 \times 10^{-6}$. 
and graft $(P<0.002)$, and progression of the rejection process (Table I). The presence of allopeptide reactive $\mathrm{T}$ cells in the circulation was predictive of rejection in 18 of 28 cases $(64 \%)$. Although at the time of LDA testing, these patients showed no histopathologic evidence of rejection, the subsequent biopsy (performed within 1-4 weeks) showed rejection grade 1B, 2 or 3. The early appearance of allopeptide-reactive Th cells in the circulation suggests that these cells play a role in initiating rejection by producing the lymphokines required for the generation of CTL, DTH and inflammatory responses. LDAs performed at the time of rejection revealed the presence of $\mathrm{T}$ cells activated by the indirect pathway in most PBMC (88\%) specimens tested. During resolving rejection, which is characterized histologically by a lesser degree of graft damage than seen before rejection treatment (28), only $35 \%$ of PBMC samples studied showed allopeptide reactive $\mathrm{T}$ cells. Ninety-four percent of LDAs were negative in patients with no histologic evidence of rejection for a period of one month, indicating that quiescence was related to the absence of allopeptide reactive $\mathrm{T}$ cells (Table I). The decreased incidence of positive LDA after treatment of acute rejection suggests that the indirect recogni- tion pathway is susceptible, at least in part, to inhibition by conventional immunosuppressive drugs (methylprednisolone and cyclosporine), consistent with other studies $(32,33)$.

Frequency and HLA-DR specificity of allopeptide reactive $T$ cells. The frequency of allopeptide-reactive $\mathrm{T}$ cells was 10 50 -fold higher within the population of $\mathrm{T}$ cells infiltrating the graft than within the subset of peripheral blood T cells selectively expanded in medium with rIL-2 (Table II). This suggests that $\mathrm{T}$ cells activated via the indirect allorecognition pathway participate actively in acute allograft rejection.

Of particular interest was the finding that although 19 of the heart recipients included in these studies were mismatched from the donor for two HLA-DR antigens, self-MHC restricted Th reactivity was directed against only one of the donor's HLA-DR antigens in 15 of these patients.

LDA studies of allopeptide reactivity showed that this biased $\mathrm{T}$ cell recognition of a single donor DR antigen occurred both in the periphery and in the graft (Table II). Because the frequency of allopeptide reactive Th cells infiltrating the graft during rejection was 10-50-fold higher, compared with the periphery, it is unlikely that the failure of recipient $\mathrm{T}$ cells to recognize the second
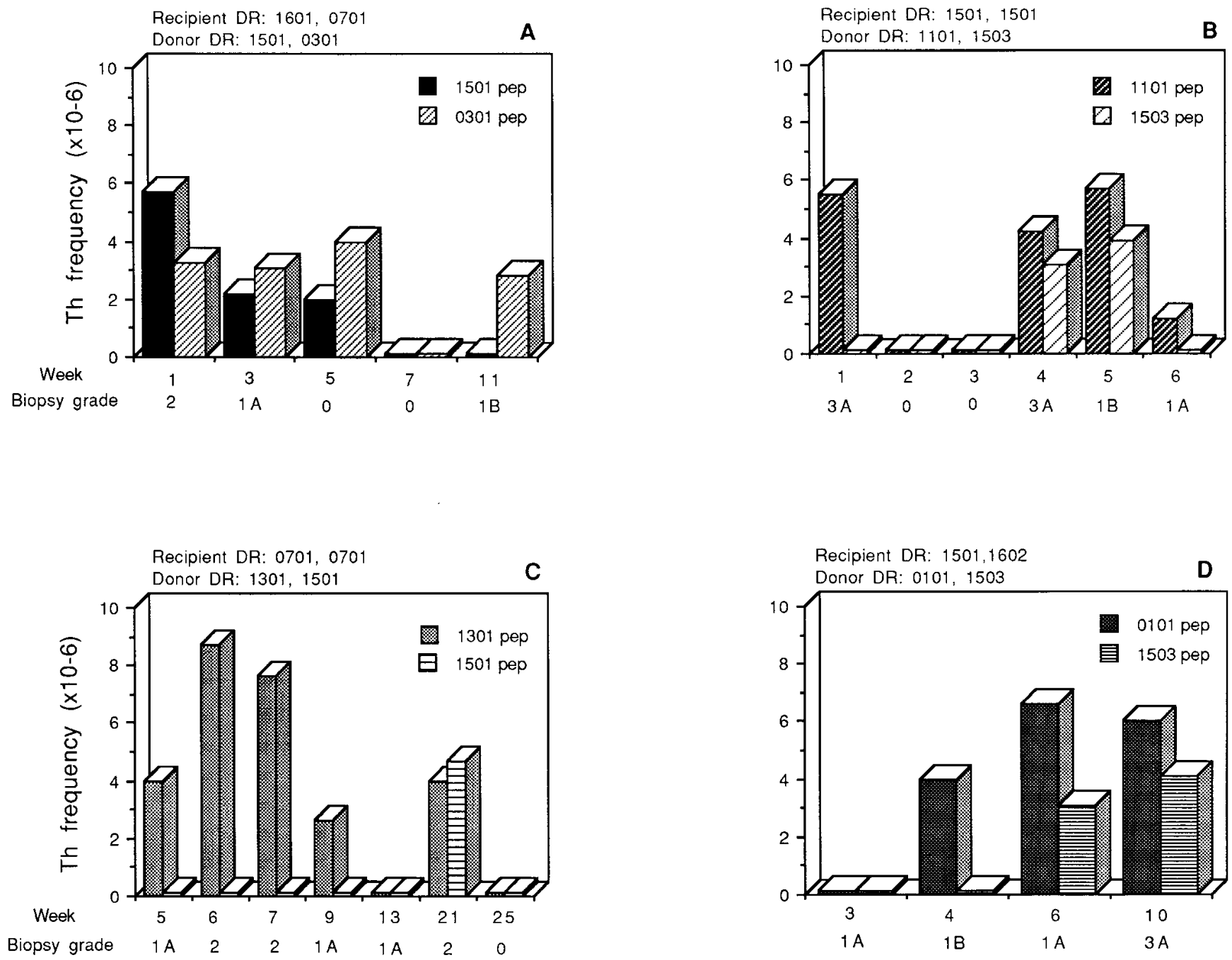

Figure 2. Intermolecular alloantigen spreading during the course of multiple acute rejection episodes. PBMCs were collected from each patient at various times after transplantation and tested in LDA for reactivity against peptides corresponding to each of the mismatched HLA-DR antigens of the donor. Th frequency was determined as described in references 23 and 30. Grading of each biopsy at the time when the blood was collected is indicated. 
mismatched HLA-DR antigen was due to the low frequency of the corresponding TCRs and/or to the insensitivity of the assay system. It is more plausible that there was differential processing and competition between allopeptides for occupancy of MHCclass II antigens on host APCs and that a single dominant allopeptide reached the stimulatory threshold (10,34-36).

However, the $\mathrm{T}$ cell response to donor antigens during allograft rejection appears to be a dynamic process. Thus, in four patients who displayed multiple rejection episodes, indirect allorecognition of both donor DR antigens occurred at various times following transplantation (Fig. 2). In only one of these patients (Fig. $2 \mathrm{~A}$ ), who was mismatched from the donor by HLA-DR $\beta 1 * 1501$ and 0301, LDA study of the peripheral blood showed Th reactivity against both DR15 and DR3 peptides throughout the first rejection episode. A second episode, occurring 11 weeks following transplantation was accompanied by reactivity against DR3 but not against DR15 peptides. In the remaining three patients alloreactivity was directed against a single donor DR antigen during the first episode, yet the response spread to include the other DR antigen during subsequent episodes of acute rejection (Fig. 2, $B-D$ ).

To identify the determinant(s) which T cells recognize during rejection, allopeptide-reactive $\mathrm{T}$ cells from LDA studies were expanded in medium containing rIL-2, autologous APCs and the mixture of stimulatory peptides corresponding to the sensitizing HLA-DR antigen. The resulting $\mathrm{T}$ cell lines were tested for reactivity to each component of the mixture in the presence of hemi-allogeneic APCs sharing with the recipient one HLA-DR antigen. These experiments showed that although six of the eight $\mathrm{T}$ cell lines studied were obtained from HLA-DR heterozygous recipients, allopeptide reactivity was restricted by a single HLA-DR element of the host (Table III). As indicated above, the response was directed against the dominant determinant of a single HLA-DR antigen, even when the donor was mismatched from the recipient by two HLA-DR alleles (Table III, patients B.C., I.P., B.R., X.J., F.J., H.M.).
Mapping of the dominant determinant of the DR $\beta 1 * 0101$ molecule recognized in vivo by $\mathrm{DR} \beta 1 * 1101$ recipients confirmed previous in vitro studies, identifying peptide $21-39$ as the dominant peptide. Seven additional dominant determinants were identified (Table III). Peptide 21-39 of DR $\beta 1 * 0101$ molecule is also the dominant $\mathrm{T}$ cell epitope recognized by $\mathrm{DR} \beta 1 * 1104$ responders. The dominant epitope of the DR $\beta 1 * 0301$ protein presented by DR $\beta 1 * 0101$ molecule is peptide $1-19$. Peptide $62-80$ of the DR $\beta 1 * 0401$ molecule is the dominant determinant presented in the context of DRß1*0701. Peptide 1-19 of the DR $\beta 1 * 1301$ protein is the dominant determinant recognized by $\mathrm{T}$ cells in the context of $\mathrm{DR} \beta 1 * 0701$. Peptide $1-19$ of the DR $\beta 1 * 1501$ molecule is the dominant determinant which $\mathrm{T}$ cells recognize in the context of DR $\beta 1 * 0401$ and DR $\beta 1 * 1104$. Finally, peptide $21-39$ of DR $\beta 1 * 1503$ is the dominant determinant recognized by DR $\beta 1 * 1501$ responders.

Based on previous studies showing that when dominant allopeptides are used at high concentration they inhibit specifically the indirect recognition response, it is expected that these newly mapped determinants may also induce high zone tolerance to the corresponding MHC molecule $(22,23)$.

\section{Discussion}

It is currently accepted that both the direct and indirect pathway of allorecognition are involved in allograft rejection. The frequency of $\mathrm{T}$ cells which directly recognize intact allo-MHC molecules on the surface of target cells is at least 100-fold higher than that of $\mathrm{T}$ cells recognizing allopeptides processed and presented by self MHC (20). This finding suggests that the direct pathway of allorecognition dominates the rejection response during the early posttransplantation period when MHC-class II antigens expressed on donor dendritic cells vigorously stimulate the $\mathrm{T}$ helper cell response of the host.

However, the role of direct allorecognition seems to diminish after passenger leukocytes of donor origin have left the

Table III. Determination of Host Restriction Element and Dominant Allopeptide

\begin{tabular}{|c|c|c|c|c|c|c|c|}
\hline \multirow[b]{2}{*}{ Patient } & \multirow[b]{2}{*}{ Recipient } & \multirow[b]{2}{*}{ HLA-DR donor } & \multirow[b]{2}{*}{ APC } & \multirow[b]{2}{*}{ DR peptide specificity } & \multicolumn{3}{|c|}{${ }^{3} \mathrm{H}-\mathrm{TdR}$ Incorporation (cpm) } \\
\hline & & & & & Peptide 1-19 & Peptide 21-39 & Peptide 62-80 \\
\hline \multirow[t]{2}{*}{ B.C. } & 0701/1101 & 0101/0401 & 0701/0701 & 0101 & 1,764 & 1,660 & 1,416 \\
\hline & & & $1101 / 1201$ & & 1,649 & 35,027 & 1,770 \\
\hline \multirow[t]{2}{*}{ I.P. } & 0404/1104 & $1101 / 1401$ & $0404 / 1501$ & 0101 & 560 & 700 & 471 \\
\hline & & & $1104 / 1502$ & & 137 & 18,360 & 860 \\
\hline \multirow[t]{2}{*}{ K.R. } & $0101 / 1501$ & 0301/0301 & 0101/0401 & 0301 & 5,075 & 112 & 293 \\
\hline & & & $1501 / 0401$ & & 108 & 117 & 192 \\
\hline \multirow[t]{2}{*}{ K.T. } & $0404 / 0701$ & $0401 / 0404$ & $0404 / 1501$ & 0401 & 1,917 & 1,926 & 1,403 \\
\hline & & & 0701/0701 & & 1,942 & 1,741 & 22,953 \\
\hline B.R. & 0701/0701 & $1301 / 1501$ & 0701/0701 & 1301 & 43,867 & 2,538 & 1,804 \\
\hline \multirow[t]{2}{*}{ X.J. } & 0101/0401 & $1101 / 1501$ & 0101/1201 & 1501 & 2,348 & 2,203 & 2,009 \\
\hline & & & $0401 / 1401$ & & 49,368 & 2,102 & 1,728 \\
\hline \multirow[t]{2}{*}{ F.J. } & $1104 / 1401$ & 0901/1501 & $1104 / 1502$ & 1501 & 5,461 & 137 & 103 \\
\hline & & & $1401 / 0401$ & & 115 & 131 & 110 \\
\hline H.M. & $1501 / 1501$ & $1101 / 1503$ & $1501 / 1501$ & 1503 & 245 & 13,286 & 259 \\
\hline
\end{tabular}

T cells, reacting in LDA to donor allopeptides, were expanded in medium containing the stimulatory peptide mixture (1 $\mu$ M of each peptide), rIL-2 $(20 \mathrm{U} / \mathrm{ml})$ and autologous APCs $\left(1 \times 10^{6}\right)$. The resulting T cell lines were tested for reactivity to each component of the mixture in the presence of APCs sharing with the recipient one HLA-DR antigen. $\left[{ }^{3} \mathrm{H}\right] \mathrm{TdrR}$ incorporation in 3-d blastogenesis assay was measured by liquid scintillation counting. Mean cpm of triplicate reactions is indicated. The SD to the mean was less than $10 \%$. 
graft $(2,3)$. Thus, experiments in rats have shown that adoptive transfer of alloreactive $\mathrm{T}$ cells, primed by the direct pathway, results in rejection of kidney allografts containing donor dendritic cells but has no effect on grafts depleted of passenger leukocytes (37).

Furthermore, although lymphokines produced by $\mathrm{T}$ helper cells, notably interferon $\gamma$, induce MHC class II expression on endothelial and epithelial cells of the graft, such defective nonprofessional APCs may anergize rather than stimulate alloreactive $\mathrm{T}$ cells $(10,38)$. In contrast to the direct recognition pathway which depends on the presence in the graft of professional APCs of donor origin, the indirect pathway is stimulated by allopeptides presented by professional APCs (dendritic cells, macrophages) of host origin. Because of the continuous supply of host APCs which have processed donor allopeptides, self-MHC restricted Th cells may perpetuate rejection, generating help for activation of CTL and alloantibody production. This may eventually result in chronic rejection, a phenomenon which claims the function of almost $50 \%$ of all organ allografts within 5 years after transplantation. The prevention of this irreversible process may require the development of novel strategies for suppression of the indirect allorecognition pathway. The exquisite specificity of self-MHC restricted T cells for the dominant determinant of allogeneic MHC molecules raises the possibility of using high doses of dominant peptide antigens for tolerance induction or of designing non-immunogenic analogs of the wild-type peptide which act as MHC blockers or TCR antagonists. However, the design of therapeutic protocols based on the use of peptides awaits a detailed understanding of the relationship between self-MHC restricted T cell alloreactivity and rejection.

To our knowledge the present study describes for the first time the kinetics of indirect allorecognition in patients with organ allografts. These investigations demonstrate that in heart transplantation the development and progression of acute rejection is strongly associated with the appearance both in the graft and in the recipient's circulation of T cells which react to donor HLA-DR peptides. Because the presence of allopeptide reactive $\mathrm{T}$ cells in the circulation was predictive of rejection, indirect alloreactivity seems to be the cause rather than the consequence of acute rejection. It is likely that following alloantigen recognition allopeptide primed $\mathrm{T}$ cells infiltrate the graft and secrete lymphokines which promote the generation of CTL, DTH and inflammatory responses characteristic of acute rejection. During resolving rejection and quiescence selfMHC restricted alloreactive $\mathrm{T}$ cells disappeared from the circulation and graft tissue, in a pattern consistent with the concept that they play an active role in the acute rejection process. Although the frequency of allopeptide reactive T cells was 1050 -fold lower in the periphery than in the graft, the finding that they were detectable in the circulation before rejection could be recognized histologically on graft biopsies opens the way to the development of non-invasive procedures for early prediction of rejection.

The strategy used for determining the frequency of allopeptide reactive $\mathrm{T}$ cells was similar to that described by Zhang et al. (30) for the detection of $\mathrm{T}$ cells reactive to myelin basic protein in patients with multiple sclerosis. Because $\mathrm{T}$ cells were cultured with IL-2 before stimulation with donor allopeptides, it may be argued that reactivity reflected the in vitro resuscitation of anergic cells. Such a mechanism implies that allopeptide reactive $\mathrm{T}$ cell clones were anergized in vivo by exposure to breakdown products of allogeneic MHC molecules (possibly presented by other T cells) $(30,39)$ and that their presence in the graft and periphery has no pathologic consequences.

Although this hypothetical situation cannot be ruled out it is unlikely to have occurred because the presence of allopeptide reactive $T$ cells in the periphery and in the graft correlated with each other and with rejection. Anergic T cells should have remained detectable during quiescence particularly in those patients who showed allopeptide reactive $\mathrm{T}$ cells during a previous rejection episode. Our failure to detect allopeptide reactive $\mathrm{T}$ cells during quiescence may reflect their low frequency and /or lack of high affinity IL-2 receptors.

However, it is conceivable that anergy may play an important role in the maintenance of allogeneic tolerance, and that high extracellular concentrations of soluble MHC alloantigens may be required for inducing it. This possibility is consistent with the finding that $\mathrm{T}$ cells reacting to self antigens, including $\mathrm{MHC}$, are present in the peripheral circulation of healthy individuals with no autoimmune conditions, and are probably maintained in a state of anergy $(40,41)$.

Of particular interest was the finding that in recipients transplanted with heart allografts mismatched for two HLADR antigens primary episodes of acute rejection appeared to be triggered by only one of the donor's HLA-DR antigens. Study of Th reactivity in the circulation and in the graft showed that the response was specific for a dominant peptide derived from the polymorphic region of one of the donor's HLA-DR antigen. Although most patients were HLA-DR heterozygous Th reactivity to donor allopeptide was restricted in all cases by a single HLA-DR element of the host.

This biased recognition of a sole allodeterminant in HLADR heterozygous donor-recipient combinations may reflect differential antigen processing and selection of specific peptides, a phenomenon presumed to be controlled by an allelic polymorphism in linkage disequilibrium with some MHC-class II genes (10, 34-36). Thus, analyses of T cell responses to selfpeptides in several $\mathrm{H}-2$ recombinant mice demonstrated that the peptide-selection for presentation to autoreactive $\mathrm{T}$ cells is controlled by genes that mapped to a $170-\mathrm{kb}$ portion of class II region of the MHC locus (42). Similarly, studies of human B cell lines with mutations in the HLA-DMA and HLA-DMB region showed that such cells manifest defective formation of class II peptide complexes. Expression of normal HLA-DMB or HLA-DMA cDNA in these mutants restored their APC function, indicating that antigen presentation is regulated by HLA-linked genes different from conventional HLA-class II $(35,36)$. It is, therefore, possible that by contributing to the selection of MHC peptides available for presentation on MHCclass II molecules, this allelic polymorphism may play an essential role in $\mathrm{T}$ cell alloreactivity.

However, the specificity of $\mathrm{T}$ cell responses to donor antigens may change during progression of rejection since in a few patients with multiple acute rejection episodes alloreactivity spread from one donor HLA-DR to the second DR antigen. This finding has important implication for the design of antigen-specific immunotherapies for the treatment of acute and chronic rejection.

It is possible that inflammation within the graft, interferon $\gamma$ production, tissue damage and upregulation of MHC expression may contribute to intermolecular antigen spreading following a rejection episode. The observation that $\mathrm{T}$ cell speci- 
ficities appear to change during the relapsing-remitting course of the alloimmune response is consistent with studies on autoimmune diseases $(10,43)$ as well as with the finding that the antibody response of transplant patients spreads from one alloantigen to another during rejection (44).

Mapping of dominant $\mathrm{T}$ cell allodeterminants is essential for the design of inhibitory peptides. Further immunogenetics analysis will be required to determine whether peptides which are dominant in the context of one HLA-DR restrictive element are cryptic when presented by the other haplotype. Although during the course of these follow-up studies no intramolecular spreading of epitopes was observed, it remains possible that determinants which are cryptic when presented by one type of APC (dendritic cells for example) become dominant when presented by other APCs (such as B cells) $(10,44)$. Furthermore, because the peptides selected in this study cover the hypervariable but not the less polymorphic region of the first domain of the DR $\beta 1$ * chain, it is possible that determinant spreading to cryptic epitopes from these less variable regions has remained undetected. It will be important to determine whether alloreactive B cells, which participate in antibody-mediated chronic rejection, activate $\mathrm{T}$ cell reactivity to such cryptic allopeptides.

Taken together, the data indicate that following transplantation $\mathrm{T}$ cells recognize processed forms of donor HLA proteins associated with a host HLA-DR restriction element. The response of in vivo activated T cells is limited to a single dominant determinant of an allogeneic MHC molecule consistent with previous studies on human $\mathrm{T}$ cells allo-activated in vitro with soluble HLA-DR proteins (22), and on T cells from mice undergoing skin allograft rejection (10).

Because $\mathrm{T}$ cell receptor $\mathrm{V} \beta$ gene usage in response to the dominant allopeptide is also limited $(21,26)$, selective immune intervention such as treatment with anti-TCR antibodies or induction of tolerance to the dominant determinant may represent viable options for specific suppression of indirect recognition. Treatment to block the indirect recognition pathway may prevent the initiation and amplification of transplant rejection, particularly after professional APCs of donor origin have left the graft, rendering it less vulnerable to direct allorecognition.

\section{Acknowledgments}

The authors acknowledge Jonathan Kinne's valuable editorial assistance.

This work was supported in part by the National Institutes of Health grant R01-AI25210-09.

\section{References}

1. Steinman, RM., and M.D. Witmer. 1978. Lymphoid dendritic cells are potent stimulators of the primary mixed leukocyte reaction in mice. Immunol. 75:5132-5136.

2. Mason, D.W., C.W. Pugh, and M. Webb. 1981. The rat mixed lymphocyte reaction: roles of a dendritic cell in intestinal lymph and T-cell subsets defined by monoclonal antibodies. Immunol. 44:75-87.

3. Lechler, R.I., and J.R. Batchelor. 1982. Restoration of immunogenicity to passenger cell-depleted kidney allografts by the addition of donor strain dendritic cells. J. Exp. Med. 155:31-41.

4. Matzinger, P. and M.J. Bevan. 1977. Hypothesis: Why do so many lymphocytes respond to major histocompatibility antigens? Cell Immunol. 29: 1-5.

5. Lechler, R.I., G. Lombardi, J.R. Batchelor, N. Reinsmoen, and F.H. Bach. 1990. The molecular basis of alloreactivity. Immunol. Today. 11:83-88.

6. Lechler, R.I., T. Heaton, L. Barber, V. Ball, J.R. Batchelor, and G. Lombardi. 1992. Molecular mimicry by major histocompatibility complex molecules and peptides accounts for some alloresponses. Immunol. Lett. 34:63-70.

7. Lo, D., L.C. Burkly, R.A. Flavell, R.D. Palmiter, and Brinster, R.L. 1989 Tolerance in transgenic mice expressing class II major histocompatibility complex on pancreatic acinar cells. J. Exp. Med. 170:87-104.

8. Gaspari, A.A., M.K. Jenkins, and S.I. Katz. 1988. Class II MHC-bearing keratinocytes induce antigen-specific unresponsiveness in hapten-specific TH1 clones. J. Immunol. 7:2216-2222.

9. Bradley, J.A. 1996. Indirect T cell recognition in allograft rejection. Int. Rev. Immunol. 13:245-255.

10. Benichou, G., and E.V. Fedoseyeva. 1996. The contribution of peptides to $T$ cell allorecognition and allograft rejection. Int Rev. Immunol. 13:231-243.

11. Benichou, G., A.P. Takizawa, A.C. Olson, M. McMillan, and E.E. Sercarz. 1992. Donor major histocompatibility complex (MHC) peptides are presented by recipient MHC molecules during graft rejection. J. Exp. Med. 175: 305-308.

12. Watschinger, B., L. Gallon, C.B. Carpenter, and M.H. Seyegh. 1994. Mechanisms of allo-recognition: Recognition by in vivo-primed $\mathrm{T}$ cells of specific major histocompatibility complex polymorphisms presented as peptides by responder antigen- presenting cells. Transplantation. 57:572-576.

13. Sayegh, M.H., and C.B. Carpenter. 1996. Role of indirect allorecognition in allograft rejection. Int Rev. Immunol. 13:221-229.

14. Dalchau, R., J. Fangmann, and J.W. Fabre. 1992. Allorecognition of isolated, denatured chains of class I and class II major histocompatibility complex molecules. Evidence for an important role for indirect allorecognition in transplantation. Eur. J. Immunol. 22:669-677.

15. Fangmann, J., R. Dalchau, and J.W. Fabre. 1992. Rejection of skin allografts by indirect allorecognition of donor class I major histocompatibility complex peptides. J. Exp. Med. 75:1521-1529.

16. Sayegh, M.H., S.J. Khoury, W.W. Hancock, H.L. Weiner, and C.B. Carpenter. 1992. Induction of immunity and oral tolerance with polymorphic class II major histocompatibility complex allopeptides in the rat. Proc. Natl. Acad. Sci. USA. 89:7762-7766.

17. Auchincloss, H. Jr., R. Lee, S. Shea, J.S. Markowitz, M.J. Grusby, and L.H. Glimcher. 1993. The role of "indirect" recognition in initiating rejection of skin grafts from major histocompatibility complex class II-deficient mice. Proc. Natl. Acad. Sci. USA. 90:3373-3377.

18. Lee, R.S., M.J. Grusby, L.H. Glimcher, H.J. Winn, and H. Auchincloss, Jr. 1994. Indirect recognition by helper cells can induce donor-specific cytotoxic T lymphocytes in vivo. J. Exp. Med. 197:865-872.

19. Parker, D.C. 1993. T cell dependent B cell activation. Ann. Rev. Immunol. 11:331-360.

20. Liu, Z., Y.K. Sun, Y.P. Xi, A. Maffei, E. Reed, P.E. Harris and N. SuciuFoca. 1993. Contribution of direct and indirect recognition pathway to T cell alloreactivity. J. Exp. Med. 177:1643-1650.

21. Liu, Z., N. Braunstein, and N. Suciu-Foca. 1992. T cell recognition of allo-peptides in context of syngeneic MHC. J. Immunol. 148:35-40.

22. Liu, Z., P. Harris, A. I. Colovai, E.F. Reed, A. Maffei, and N. SuciuFoca. 1995. Suppression of the indirect pathway of $\mathrm{T}$ cell reactivity by high doses of allopeptide. Autoimmunity. 21.173-184.

23. Liu, Z., P. Harris, A.I. Colovai, E.F. Reed, A. Maffei, and N. SuciuFoca. 1996. Indirect recognition of donor MHC-class II antigens in human transplantation. Clin. Immunol. and Immunopathol. Vol. 78. In press.

24. Colovai, A.I., E. Renna-Molajoni, R. Cortesini, and N. Suciu-Foca. 1996. New approaches to specific immunomodulation in transplantation. Int. Rev. Immunol. 13:161-172.

25. Benichou, G., E. Fedoseyeva, P.V. Lehmann, C.A. Olson, H.M. Geysen, M. McMillian, and E.E. Sercarz. 1994. Limited T cell response to donor MHC peptides during allograft rejection. J. Immunol. 153:938-941.

26. Liu, Z., Y.K. Sun, Y.P. Xi, B. Hong, P.E. Harris, E.F. Reed, and N Suciu-Foca. 1993. Limited usage of TCR V $\beta$ genes by allopeptide specific T cells. J. Immunol. 150:3180-3186.

27. Fisher, P.E., N. Suciu-Foca, E. Ho, R.E. Michler, E.A. Rose, and M. Mancini. 1995. Additive value of immunologic monitoring to histologic grading of heart allograft biopsy specimens: implications for therapy. J. Heart \& Lung Transplant. 14:1156-1161.

28. Billingham, M.D. 1995. Pathology of human cardiac transplantation. In: Cardiovascular pathology. Clincopathologic correlations and pathogenetic mechanisms. F.S. Schoen and M.A. Gimbrone, Jr., editors, Williams and Wilkins, Baltimore, MD. 108-129.

29. Bodmer, J.G., S. G. E. Marsh, E.D. Albert, W. F. Bodmer, B. Dupont, H.A. Erlich, B. Mach, W.R. Mayr, P. Parham, T. Sasazuki, G.M. Schreuder, J.L. Strominger, A.Svejgaard, and P.I. Terasaki. 1994. Nomenclature for factors of the HLA system. Human Immunol. 41:1-20.

30. Zhang, J., S. Markovic-Plese, B. Lacet, J. Raus, H.L. Weiner, and D.A. Hafler. 1994. Increased frequency of interleukin 2-responsive T cells specific for myelin basic protein and proteolipid protein in peripheral blood and cerebrospinal fluid of patients with multiple sclerosis. J. Exp. Med. 179:973-984.

31. Dixon, W.J., M.B. Brown, L. Engelman, R.I. Jennrich. 1990. BMDP statistical software manual to accompany the 1990 software release, Berkeley University of California Press.

32. Sawyer, G.J., R. Dalchau, and J.W. Fabre. 1993. Indirect T cell allorecognition: a cyclosporin A resistant pathway for T cell help for antibody produc- 
tion to donor MHC antigens. Transplant. Immunol. 1:77-81.

33. Gallon, L., B. Watschinger, B. Murphy, E. Akalin, M.H. Sayegh, and C.B. Carpenter. 1995. The indirect pathway of allorecognition. In The Occurrence of Self-restricted T Cell Recognition of Allo-MHC Peptides Early in Acute Renal Allograft Rejection and Its Inhibition by Conventional Immunosuppression. Transplantation. 59:612-616.

34. Barbey, C. C. Watts, and G. Corradin. 1995. Antigen-processing organelles from DR $\beta 1 * 1101$ and DR $\beta 1 * 1104$ B cell lines display a differential degradation activity. Eur. J. Immunol. 25:30-36.

35. Fling, S., B. Arp, and D. Pious. 1994. HLA-DMA and -DMB genes are both required for MHC class II peptide complex formation in antigen-presenting cells. Nature (Lond.). 368:554-558.

36. Morris, P., J. Shaman, M. Attaya, M. Amaya, S. Goodman, C. Bergman, J. Monaco, and E. Mellins. 1994. An essential role for HLA-DM in antigen presentation by class II major histocompatibility molecules. Nature (Lond.). 368: $551-553$.

37. Braun, Y.M., A. McCormack, G. Webb, and J.R. Batchelor. 1993. Mediation of acute but not chronic rejection of MHC-incompatible rat kidney grafts by alloreactive CD4 $\mathrm{T}$ cells activated by the direct pathway of sensitization. Transplantation. 55:117-182.

38. Vidard, L., K.R. Rock, and B. Benacerraf. 1992. Heterogeneity in antigen processing of different types of antigen presenting cells. J. Immunol. 149:
1905-1911.

39. LaSalle, J.M., P.J. Tolentino, G.J. Freeman, L.M. Nadler, and D.A. Hafler. 1992. Early signaling defects in human T cells anergized by $\mathrm{T}$ cell presentation of autoantigen. J. Exp. Med. 176:177-186.

40. Ota, K., M. Matsui, E.L. Milford, G.A. Mackin, H.L. Weiner, and D.A Hafler. 1990. T cell recognition of an immunodominant myelin basic protein epitope in multiple sclerosis. Nature (Lond.). 346:183-187.

41. Liu, Z., Y.K. Sun, Y.P. Xi, P. Harris, and N. Suciu-Foca. 1992. T cell recognition of self-human histocompatibility leukocyte antigens (HLA)-DR peptides in context of syngeneic HLA-DR molecules. J. Exp. Med. 175:1663-1668.

42. Fedoseyeva, E.V., R.C. Tam, P.L. Orr, M.R. Garovoy, and G. Benichou. 1995. Presentation of a self-peptide for in vivo tolerance induction of $\mathrm{CD}^{+} \mathrm{T}$ cells is governed by a processing factor that maps to the class II region of the major histocompaibility complex locus. J. Exp. Med. 182:1481-1491.

43. McRae, B.L., C.L. Vanderlugt, M.C. Cal Canto, and S.D. Miller. 1995. Functional evidence for epitope spreading in the relapsing pathology of experimental autoimmune encephalomyelitis. J. Exp. Med. 182:75-85.

44. Suciu-Foca, N., E. Reed, V.D. D'Agati, E. Ho, D.J. Cohen, A.I. Benvenisty, R. McCabe, J.M. Brensilver, D.W. King, and M.A. Hardy. 1991. Soluble HLA antigens, anti-HLA antibodies and anti-idiotypic antibodies in the circulation of renal transplant recipients. Transplantation. 51:593-601. 